\title{
Influence of Luting Materials on the Retention of Cemented Implant-Supported Crowns: An In Vitro Study
}

\author{
Ella A. Naumova ${ }^{1, *}$, Felix Roth ${ }^{2}$, Berit Geis ${ }^{3}$, Christine Baulig ${ }^{3}$, Wolfgang H. Arnold ${ }^{1}$ (i) and \\ Andree Piwowarczyk ${ }^{2}$ \\ 1 Department of Biological and Material Sciences in Dentistry, School of Dentistry, Faculty of Health, \\ Witten/Herdecke University, Alfred-Herrhausen-Strasse 44, 58455 Witten, Germany; \\ Wolfgang.Arnold@uni-wh.de \\ 2 Department of Prosthodontics and Dental Technology, School of Dentistry, Faculty of Health, \\ Witten/Herdecke University, Alfred-Herrhausen-Strasse 44, 58455 Witten, Germany; \\ Felix.Roth@uni-wh.de (F.R.); Andree.Piwowarczyk@uni-wh.de (A.P.) \\ 3 Institute for Medical Biometry and Epidemiology, Witten/Herdecke University, Alfred-Herrhausen-Strasse 50, \\ 58455 Witten, Germany; Berit.Geis@uni-wh.de (B.G.); Christine.Baulig@uni-wh.de (C.B.) \\ * Correspondence: Ella.Naumova@uni-wh.de; Tel.: +49-2302-926-640
}

Received: 28 August 2018; Accepted: 25 September 2018; Published: 28 September 2018

\begin{abstract}
The retention force of cemented crowns on implant abutments with various luting materials was evaluated. Cobalt-chromium crowns were cemented onto tapered titanium abutments (Camlog) with eugenol-free temporary cement (RelyX TempBond NE), composite-based temporary cement (Bifix Temp), zinc phosphate cement (Harvard Cement), glass-ionomer cements (Meron, Fuji I), and resin-modified glass-ionomer cements (Fuji II, Fuji Plus, Ketac Cem Plus). Specimen aging via hydrostress was performed in artificial saliva at $37^{\circ} \mathrm{C}$ for 14 days (S1), followed by hydrothermal stress with thermocycling (S2). The crowns were removed, and the force was recorded (T1). Subsequently, the crowns were recemented, aged, and removed, and the force was recorded (T2, T3). The retention forces differences were statistically significant according to the storage conditions at T1 $(p=0.002)$ and T3 $(p=0.0002)$. After aging (S1), Ketac Cem Plus had the highest retention force median value difference (T3 versus T1) $(-773 \mathrm{~N})$, whereas RelyX TempBond NE had the lowest $(-146 \mathrm{~N})$. After aging (S2), Meron had the highest retention force median value difference $(-783 \mathrm{~N})$, whereas RelyX TempBond NE had the lowest $(-168 \mathrm{~N})$. Recementation decreased the retention force of the implant-supported cobalt-chromium crowns cemented and recemented with the same luting materials. Luting materials (at T1) and aging conditions significantly impacted the retention force.
\end{abstract}

Keywords: luting materials; implant-supported cobalt-chromium crowns; hydrothermal stress; recementation; retention force

\section{Introduction}

Oral dental implant science encompasses numerous topics of interest and evolving thematic trends in clinical studies [1]. Since the 2000s, the focus of dental implant treatment has been biological-driven therapy that recovers and maintains the function, long-term stability, and aesthetics of soft and hard peri-implant tissues [2,3]. Knowledge of the factors that influence the soft and hard peri-implant tissues' long-term safety and stability has crucial clinical relevance and significance. These factors can be divided into three groups: clinical [4], biological, and technical $[4,5]$. The biological factors are age, systemic health, medication, oral disease [4], bone support [6], occlusion [7], hard and soft peri-implant tissue quality [4], changes [8] in bacterial colonization around implants and around 
teeth, type of the oral hygiene $[3,9,10]$, and smoking [4]. The technical factors include amount of retention [11], devices for implant-supported prosthesis retention [12], type of retention force applied [13], crown and implant abutment materials, geometry, height, type of the surface finishing, surface roughness [14-16], cleaning method during recementation [17], and the chemical, physical, bioactive and "remove-on-demand" properties of the luting material $[11,12,16]$. One of the actual topics of interest in the field of biology-driven implant therapy is implant restoration [2,18,19], and this topic has induced the development of new methods and luting materials for implant-supported prosthesis retention $[11,20]$.

There are various reasons for implant restoration. During the application of pressure on the crown occlusal surface, complications such as chipping of the alveolar bone or peri-implantitis can occur, and these complications can require the retrieval of the crowns [21]. As a consequence of the disconnection of the crown, abutment and implant damage can occur and may increase the loss of the implant [22]. Three types of retention of fixed dental implant-supported prosthesis-like crowns are described in the literature: screw retention, cement retention $[6,12,23,24]$, and a combination of both [25,26]. Each type of retention has advantages and disadvantages. Screw-retained restorations are easily retrievable [27] and have fewer technical and biologic complications overall but are expensive [7]. Cemented implant-supported prostheses with a screw access hole in the metal framework improve the survival rates over time and lower the costs of implant-supported prostheses [26]. There are complications, such as disconnection of cement-retained implant-supported prostheses from abutments; nevertheless, this retention mode is still used because it is an effective option, especially for implant-supported single crowns and short-span fixed dental prostheses [18], and because of esthetic and economic reasons [28]. There is a need for the development of new modified luting materials for implant-supported prosthesis retention [11]. Three luting agent types for cement retention are known: temporary, permanent, and semipermanent $[11,29,30]$. Temporary cements, with low tensile strength and high solubility, help to avoid damaging the restoration and peri-implant tissues [31,32]. Permanent cements with high tensile strength and low solubility induce the opposite mechanical and clinical effects [33]. Semipermanent retention provides adequate retention and retrievability [29]. For semipermanent retention cements, phase change materials (PCM) were created with a phase transition behavior (solid-liquid) depending on temperature or other physical factors $[11,29,30]$. The matrix of the conventional permanent cement can be changed with activatable microadditives and can acquire new mechanical "remove-on-demand" properties [11,29,30].

Information regarding the retention forces is very important for implant restoration protocols [2]. The aim of this in vitro study was to evaluate the influence of various luting materials after differential artificial aging on the retention of implant-supported cobalt-chromium crowns cemented and recemented with the same luting materials. The primary aim of this in vitro study was the comparison of the required retention forces of the various luting materials under two different aging conditions at three retention measurement time-points. The secondary aim was the evaluation of the influence of the luting materials and aging conditions on the retention force for all retention measurement time-points (T1-T3). The null hypothesis of this in vitro study was that there are no differences between the mean retention forces of the various luting materials at three retention measurement time-points of the implant-supported cobalt-chromium crowns cemented and recemented with the same luting materials.

\section{Materials and Methods}

\subsection{Preparation of Test Bodies}

Camlog logfit abutments ( $6^{\circ}$ converging angle, $4.3 \mathrm{~mm}$ diameter, $5.8 \mathrm{~mm}$ height) were screwed with Camlog model implants (Altatec, Wimsheim, Germany). One Camlog logfit abutment (LOT 000034680) was scanned with a model scanner D800 (3 Shape, Copenhagen, Denmark), and a stereolithographic (STL) file was produced. Using dental designer software (18.1) (3 Shape, Copenhagen, Denmark), the STL file of the abutment was used for the crown design for the subsequent standardized decementation (Figure 1). 


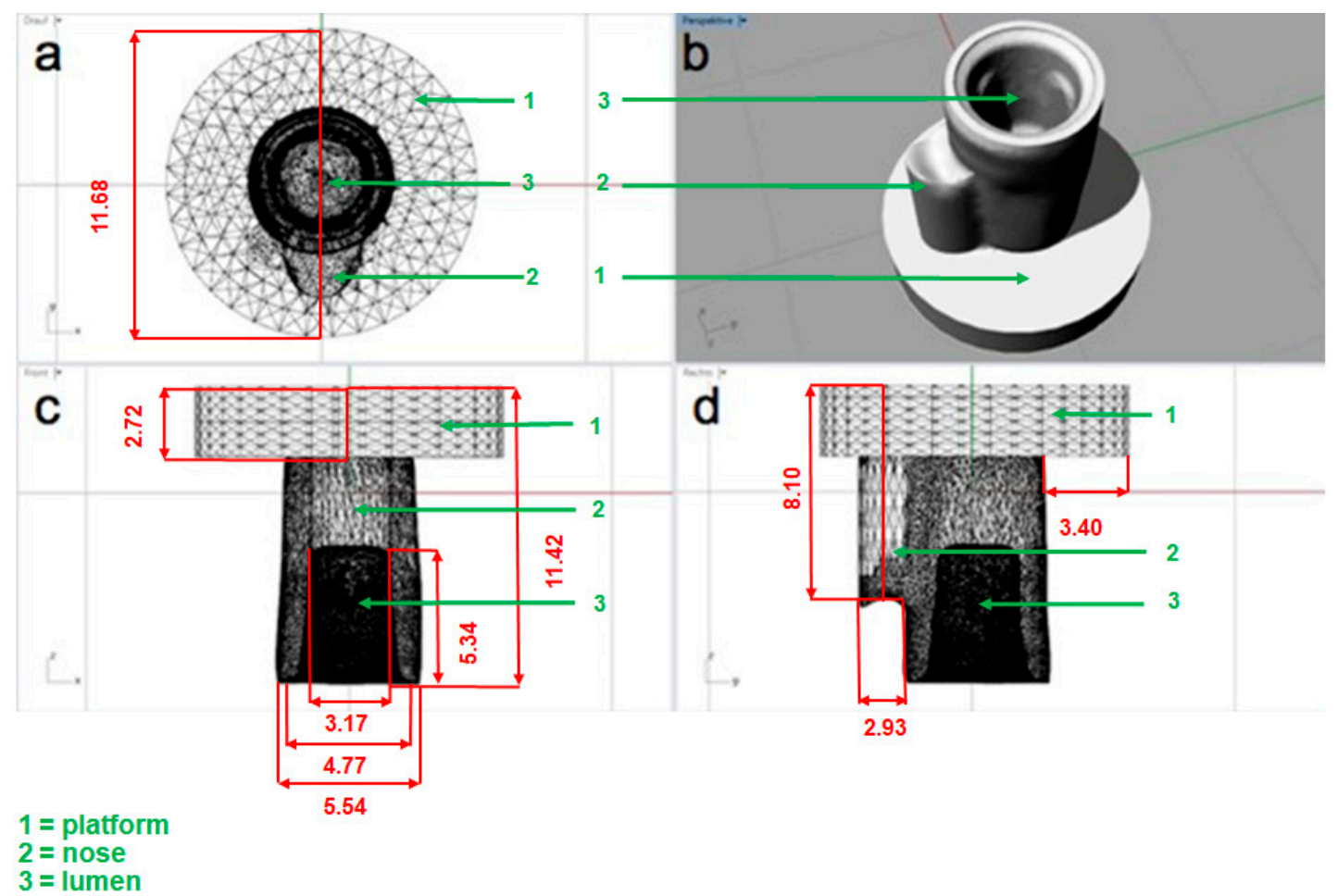

Figure 1. View of the design using the Dental-Designer software (3 shape, Copenhagen, Denmark) with above (a), transverse (b), and sidelong (c,d) views of the crown. All sizes are in $\mathrm{mm}$.

\subsection{Cobalt-Chromium Crowns and Luting Materials}

Cobalt-chromium crowns were produced by using laser-sintering from a cobalt-chromium alloy (Compartis Co-Cr; Degudent, Hanau, Germany). Cobalt-chromium crowns ( $n=128)$ were randomly divided into eight groups $(n=16)$ for standardized cementation onto the corresponding abutments with the following luting materials: one eugenol-free temporary RelyX TempBond NE cement (3M Oral Care, Seefeld, Germany); one composite-based temporary Bifix Temp cement (Voco, Cuxhaven, Germany); one zinc phosphate Harvard cement (Hoffmann Dental, Hoppegarten, Germany); two glass-ionomer cements, i.e., Meron (Voco, Cuxhaven, Germany) and Fuji I (GC, Tokyo, Japan); three resin-modified glass-ionomer cements, i.e., Fuji II (GC, Tokyo, Japan), Fuji Plus (GC, Tokyo, Japan), and Ketac Cem Plus (3M Oral Care, Seefeld, Germany) (Table 1). The cobalt-chromium crowns in all eight groups $(n=16)$ were prepared using standardized cementing with a weight of $6 \mathrm{~kg}$ on the abutments. 
Table 1. Description of the luting materials used in this study

\begin{tabular}{|c|c|c|c|c|}
\hline Material & Type & Chemical Composition $^{a}$ & Application & Manufacturer \\
\hline RelyX TempBond NE & temporary eugenol-free cement & $\begin{array}{c}\text { P: zinc oxide } \\
\text { L: white mineral Oil (Petroleum) }\end{array}$ & paste/paste & 3M Oral Care, Seefeld, Germany \\
\hline Meron & permanent glass ionomer cement & $\begin{array}{l}\text { P: fluoraluminosilicate glass } \\
\text { L: polyacrylic acid }\end{array}$ & capsule & VOCO, Cuxhaven, Germany \\
\hline Harvard Cement & permanent zinc phosphate cement & $\begin{array}{l}\text { P: zinc oxide, magnesia } \\
\text { L: phosphoric acid }\end{array}$ & powder/liquid & Hoffmann Dental, Hoppegarten, Germany \\
\hline Fuji I & permanent glass ionomer cement & $\begin{array}{l}\text { P: fluoroaluminosilicate glass } \\
\text { L: polyacrylic acid }\end{array}$ & powder/liquid & GJ, Tokyo, Japan \\
\hline Fuji II & permanent resin-modified glass ionomer cement & $\begin{array}{l}\text { P: fluoroaluminosilicate glass } \\
\text { L: methacrylated polyacrylic acid }\end{array}$ & paste/paste syringe & GJ, Tokyo, Japan \\
\hline Fuji Plus & permanent resin-modified glass ionomer cement & $\begin{array}{l}\text { P: fluoraluminosilicate glass } \\
\text { L: methacrylated polyacrylic acid }\end{array}$ & capsule & GJ, Tokyo, Japan \\
\hline Bifix Temp & temporary composite-based cement & $\begin{array}{l}\text { B: triethylene glycol dimethacrylate } \\
\text { C: benzolperoxid }\end{array}$ & paste/paste & VOCO, Cuxhaven, Germany \\
\hline Ketac Cem Plus & permanent resin-modified glass ionomer cement & $\begin{array}{l}\text { P: fluoroaluminosilicate glass } \\
\text { L: methacrylated polyacrylic acid }\end{array}$ & paste/paste syringe & 3M Oral Care, Seefeld, Germany \\
\hline
\end{tabular}

a, according to the information provided by the manufacturers. Abbreviations, $\mathrm{P}=$ powder; $\mathrm{L}=$ liquid; $\mathrm{B}=$ base; $\mathrm{C}=$ catalyst. 


\subsection{Artificial Aging after Hydro- and Hydrothermal Stress}

To simulate the oral cavity medium and its impact on the luting characteristics of the tested materials immediately after cementation, all specimens were divided according to storage conditions into two groups (S1 and S2): one-half of the specimens (S1) ( $n=8$ for every material group) were subjected to hydrostress (HS) induced by storage at $37^{\circ} \mathrm{C}$ for 14 days in $100 \mathrm{~mL}$ of artificial saliva (Dental center, Erfurt, Germany) [16]. The other half of the specimens (S2) ( $n=8$ for every material group) were subjected first to hydrostress (HS) and then to hydrothermal stress (HTS), accomplished by thermocycling in a Thermocycler THE1000 (SD Mechatronics, Feldkirchen Westerham, Germany) with 5000 cycles in water baths at temperatures of $5{ }^{\circ} \mathrm{C}$ and $55^{\circ} \mathrm{C}$ (resistance time $30 \mathrm{~s}$, dripping time $15 \mathrm{~s}$ ), followed by evaluation of the retention force of the cemented crowns on the implant abutments with the various luting materials.

\subsection{Retention Force Measurement}

After HS (group S1) or HS and following HTS (group S2) using the universal testing machine Texture Analyse HD (Stable Micro Systems, Goldaming, UK), a pull-off test for removing the cobalt-chromium crowns from the abutments at a constant speed of $1 \mathrm{~mm} / \mathrm{min}$ was performed. The maximum force of the cement failure load in Newtons $(\mathrm{N})$ was recorded (first retention measurement time-point (T1)).

The blasting agent used for sandblasting with the Basic quattro IS (Renfert, Hilzingen, Germany) was aluminum oxide $\mathrm{Al}_{2} \mathrm{O}_{3}$ (Orbis, Muenster, Germany) with a particle size of $50 \mu \mathrm{m}$ and pressure of 1.0 bar. The plate or the model analogue was manually fixed on the bottom of the blasting basket and blasted at a $45^{\circ}$ angle at a distance of $3 \mathrm{~cm}$ for approximately $10 \mathrm{~s}$. These values were constantly checked with a set square. After sandblasting, the cobalt-chromium crowns were cemented again with the same luting material, aged by HS (group S1) or by HS and HTS (group S2), and then removed. The cementation-aging-removing cycle for every crown-abutment pair was repeated a total of three retention measurement time-points (T1-T3); for these three retention time-points (T1-T3), the maximum force of the cement failure load $(\mathrm{N})$ was recorded.

\subsection{Statistics}

To evaluate the primary hypothesis, a one-way ANOVA with repeated measures was used at a $5 \%$ significance level. Data were described according to the scale level, i.e., medians and quartiles for continuous variables. Multivariate linear regression models were fitted for the target variable retention force to evaluate the impact of the luting material and aging condition at each retention measurement time-point; the results of the fitted models are presented by regression coefficients with related standard errors and $95 \%$ confidence intervals as well as results of the Wald test.

The statistical software package SPSS (Statistical Package for Social Sciences, IBM, Armonk, NY, USA) Vers. 23 and R (R Core Team, Vienna, Austria) Vers. 3.3.2 were used.

\section{Results}

\subsection{Primary Analysis}

A repeated measures ANOVA with a Greenhouse-Geisser correction determined that the mean retention forces differed significantly between measurements: $\mathrm{F}(1.43,160.44)=2816.40, p<0.001$. Bonferroni-adjusted pairwise comparisons revealed significant differences in retention forces at each retention measurement time-point (Table 2). 
Table 2. Bonferroni-adjusted pairwise comparisons of mean differences in retention force. T1, T2, T3: retention measurement time-points.

\begin{tabular}{ccccc}
\hline Retention Measurement Time-Point & Mean Difference & Standard Error & $\boldsymbol{p}$-Value \\
\hline T1 & T2 & 401.455 & 7.768 & $<0.001$ \\
T1 & T3 & 461.429 & 7.559 & $<0.001$ \\
T2 & T3 & 59.974 & 4.077 & $<0.001$ \\
\hline
\end{tabular}

Between-subject significant differences of luting materials and storage conditions were detected, $p$ $<0.001$. Since each within-subject and between-subject effect was statistically significant, multivariate regression analyses were used to investigate the impact of all luting materials and storage conditions on the retention force at T1, T2, and T3, separately. Harvard was treated as the reference material.

At T1, RelyX Temp Bond NE, Meron, Fuji I, Fuji II, and Bifix Temp showed significant increases or decreases in the retention force in comparison to Harvard at a local $5 \%$ significance level; hydrothermal stress caused a significant decrease in comparison to hydrostress (Table 3).

Table 3. T1: Multivariate linear regression analysis to investigate the impact of all luting materials and storage conditions on the retention force.

\begin{tabular}{ccccccc}
\hline Covariable & Regression Coefficient & Standard Error & $\mathbf{T}$ & $p$-Value & Lower 95\%-CI & Upper 95\%-CI \\
\hline (Intercept) & 726.98 & 33.14 & 21.94 & $<0.001$ & 661.37 \\
RelyX Temp Bond NE & -462.24 & 44.18 & -10.46 & $<0.001$ & -549.72 & -374.75 \\
Meron & 263.04 & 44.18 & 5.95 & $<0.001$ & 175.56 & 350.53 \\
Fuji I & 213.52 & 44.18 & 4.83 & $<0.001$ & 126.03 & 301.00 \\
Fuji II & 101.09 & 44.18 & 2.29 & 0.024 & 13.61 & 188.58 \\
Fuji Plus & -68.49 & 44.18 & -1.55 & 0.124 & -155.98 & 18.99 \\
Bifix Temp & -313.95 & 44.18 & -7.11 & 0.001 & -401.44 & -226.47 \\
Ketac Cem Plus & -4.12 & 44.18 & -0.09 & 0.926 & -91.60 & 83.37 \\
Hydrothermal Stress & -150.82 & 22.09 & -6.83 & $<0.001$ & -194.56 & -107.07 \\
\hline
\end{tabular}

At T2, RelyX Temp Bond NE, Meron, Bifix Temp, and Ketac Cem Plus showed significant decreases in the retention force in comparison to Harvard at a local 5\% significance level; hydrothermal stress caused a significant decrease in comparison to hydrostress (Table 4).

Table 4. T2: Multivariate linear regression analysis to investigate the impact of all luting materials and storage conditions on the retention force.

\begin{tabular}{ccccccc}
\hline Covariable & Regression Coefficient & Standard Error & $\mathbf{T}$ & $p$-Value & Lower 95\%-CI & Upper 95\%-CI \\
\hline (Intercept) & 285.62 & 12.13 & 23.55 & $<0.001$ & 261.60 & 309.63 \\
RelyX Temp Bond NE & -218.62 & 16.17 & -13.52 & $<0.001$ & -250.54 & -186.59 \\
Meron & -47.57 & 16.17 & -2.94 & 0.004 & -79.59 & -15.55 \\
Fuji I & -12.59 & 16.17 & -0.78 & 0.438 & -44.62 & 19.43 \\
Fuji II & -10.90 & 16.17 & -0.67 & 0.502 & -42.92 & 21.12 \\
Fuji Plus & -28.16 & 16.17 & -1.74 & 0.084 & -60.19 & 3.86 \\
Bifix Temp & -84.71 & 16.17 & -5.24 & $<0.001$ & -116.73 & -52.69 \\
Ketac Cem Plus & -34.25 & 16.17 & -2.12 & 0.036 & -66.28 & -2.23 \\
Hydrothermal Stress & -29.59 & 8.09 & -3.66 & $<0.001$ & -45.60 & -13.58 \\
\hline
\end{tabular}

At T3, RelyX Temp Bond NE, Bifix Temp, and Ketac Cem Plus showed significant decreases in the retention force in comparison to Harvard at a local $5 \%$ significance level; hydrothermal stress caused a significant decrease in comparison to hydrostress (Table 5). 
Table 5. T3: Multivariate linear regression analysis to investigate the impact of all luting materials and storage conditions on the retention force.

\begin{tabular}{ccccccc}
\hline Covariable & Regression Coefficient & Standard Error & $\mathbf{T}$ & $p$-Value & Lower 95\%-CI & Upper 95\%-CI \\
\hline (Intercept) & 204.36 & 8.47 & 24.12 & $<0.001$ & 187.59 & 221.14 \\
RelyX Temp Bond NE & -149.63 & 11.30 & -13.25 & $<0.001$ & -172.00 & -127.26 \\
Meron & -11.95 & 11.30 & -1.06 & 0.293 & -34.32 & 10.43 \\
Fuji I & -3.17 & 11.30 & -0.28 & 0.779 & -25.54 & 19.20 \\
Fuji II & -5.30 & 11.30 & -0.47 & 0.640 & -27.67 & 17.07 \\
Fuji Plus & 2.04 & 11.30 & 0.18 & 0.857 & -20.33 & 24.41 \\
Bifix Temp & -29.62 & 11.30 & -2.62 & 0.010 & -51.99 & -7.25 \\
Ketac Cem Plus & -34.57 & 11.30 & -3.06 & 0.003 & -56.94 & -12.20 \\
Hydrothermal Stress & -38.18 & 5.65 & -6.76 & $<0.001$ & -49.37 & -27.00 \\
\hline
\end{tabular}

\subsection{Comparison of Retention Forces at $\mathrm{T} 1, \mathrm{~T} 2$, and $\mathrm{T} 3$}

At T1, the required retention force was considerably higher than at T2 or T3 (Table 6). In general, the retention force was continuously reduced from T1 to T3. The median retention force at T1 (independent of luting material or storage condition) was $619.20 \mathrm{~N}$, with an interquartile range (IQR) of 410.40-852.20 N. At T2, the median force decreased to $226.70 \mathrm{~N}$ (IQR 190.00-259.20 N); therefore, the lowest force, corresponding to $162.80 \mathrm{~N}$ (IQR 132.30-198.60 N), was reached at T3 (Figure 2).

Table 6. Descriptive data of the statistical evaluation of the retention force (in N).

\begin{tabular}{cccccccc}
\hline Retention Measurement Time-Point & Minimum & 1st Quartile & Median & Mean Value & SD & 3rd Quartile & Maximum \\
\hline T1 & 119.70 & 410.40 & 619.20 & 617.70 & 273.65 & 852.20 & 1148.00 \\
T2 & 27.28 & 190.00 & 226.70 & 216.20 & 81.67 & 259.20 & 399.30 \\
T3 & 10.45 & 132.30 & 162.80 & 156.20 & 59.83 & 198.60 & 279.40 \\
\hline
\end{tabular}

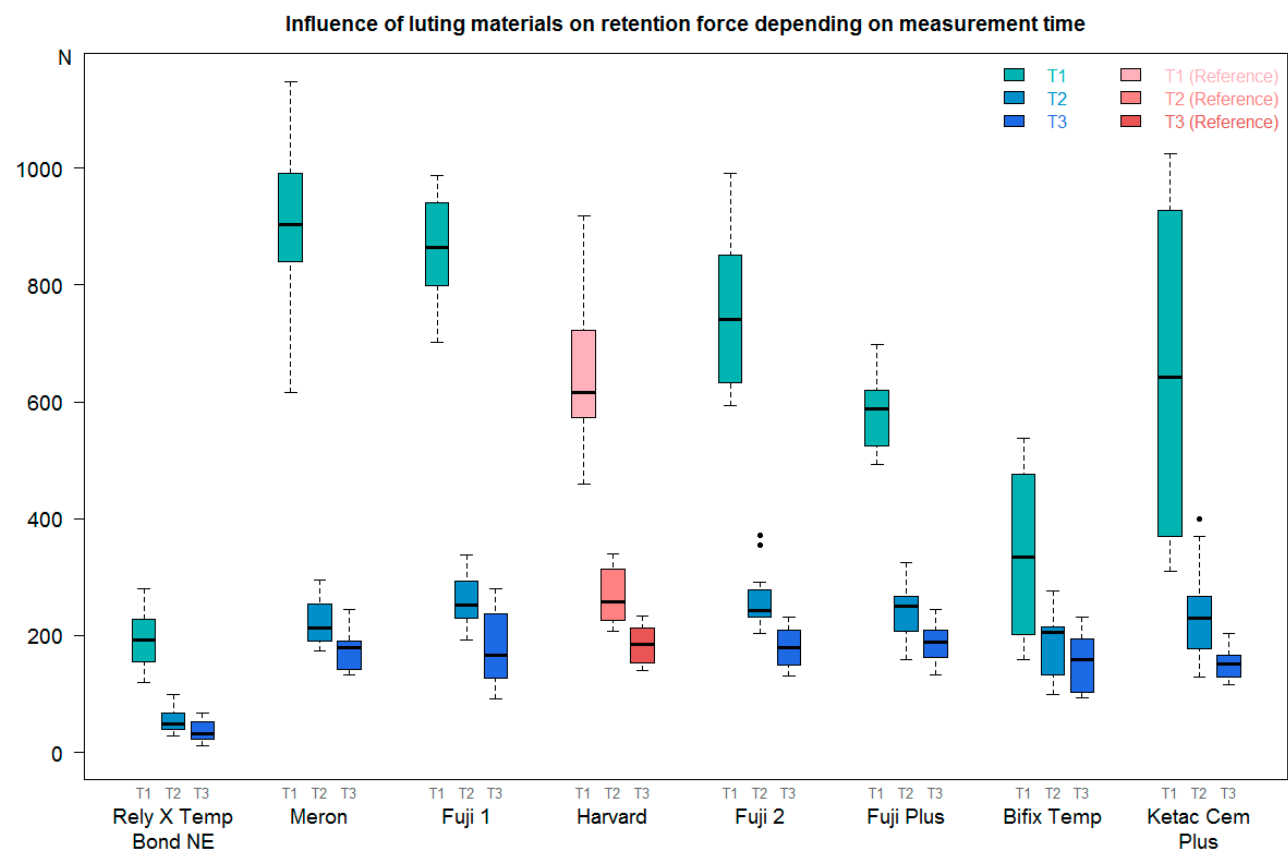

Figure 2. Comparison of the retention force at T1-T3 independent of the storage conditions. Boxes indicate the data's location and variation. One box includes $50 \%$ of the analyzed data; the line within the box indicates the median.

\subsection{Comparison of Retention Forces at T1, T2, and T3 for Luting Materials Independent of the Storage Conditions}

At T1, the luting material RelyX Temp Bond NE achieved the minimum retention force required (Table 7, Figure 3). Temp Bond NE showed the lowest median retention force (191.70 N; IQR 
155.60-224.39 N), while Meron showed the highest (902.30 N; IQR 848.40-973.90 N). Ketac Cem Plus had the highest standard deviation of the mean retention force $( \pm 295.46 \mathrm{~N})$.

Table 7. Descriptive data of the statistical evaluation of the retention force at $\mathrm{T} 1$ independent of the storage conditions (in $\mathrm{N}$ ).

\begin{tabular}{cccccccc}
\hline \multirow{2}{*}{ Luting Material } & \multicolumn{7}{c}{ T1 } \\
\cline { 2 - 7 } & Minimum & 1st Quartile & Median & Mean Value & SD & 3rd Quartile & Maximum \\
\hline RelyX & & & & & & & \\
Temp & 119.70 & 155.60 & 191.70 & 189.30 & 47.47 & 224.39 & 280.90 \\
Bond NE & & & & & & & \\
Meron & 615.20 & 848.30 & 902.30 & 914.60 & 130.90 & 973.90 & 1148.00 \\
Fuji I & 702.30 & 800.50 & 863.60 & 865.10 & 87.44 & 936.20 & 987.90 \\
Harvard & 459.10 & 575.90 & 615.80 & 651.60 & 129.90 & 711.30 & 919.00 \\
Fuji II & 593.30 & 636.60 & 740.10 & 752.70 & 135.13 & 829.50 & 991.70 \\
Fuji Plus & 492.50 & 528.40 & 588.50 & 583.10 & 62.66 & 617.80 & 698.20 \\
Bifix & 158.30 & 204.00 & 334.50 & 337.60 & 137.92 & 466.40 & 538.30 \\
Temp & 310.00 & 370.80 & 642.20 & 647.50 & 295.46 & 899.80 & 1024.00 \\
Ketac Cem Plus & & & & & & &
\end{tabular}

At T2, RelyX Temp Bond NE had the lowest median retention force (49.09 N; IQR 38.89-65.89 N), and Harvard had the highest (258.10 N; IQR 225.70-308.70 N). Ketac Cem Plus reached the highest maximum retention force $(399.30 \mathrm{~N})$. The results are shown in Table 8 and Figure 3.

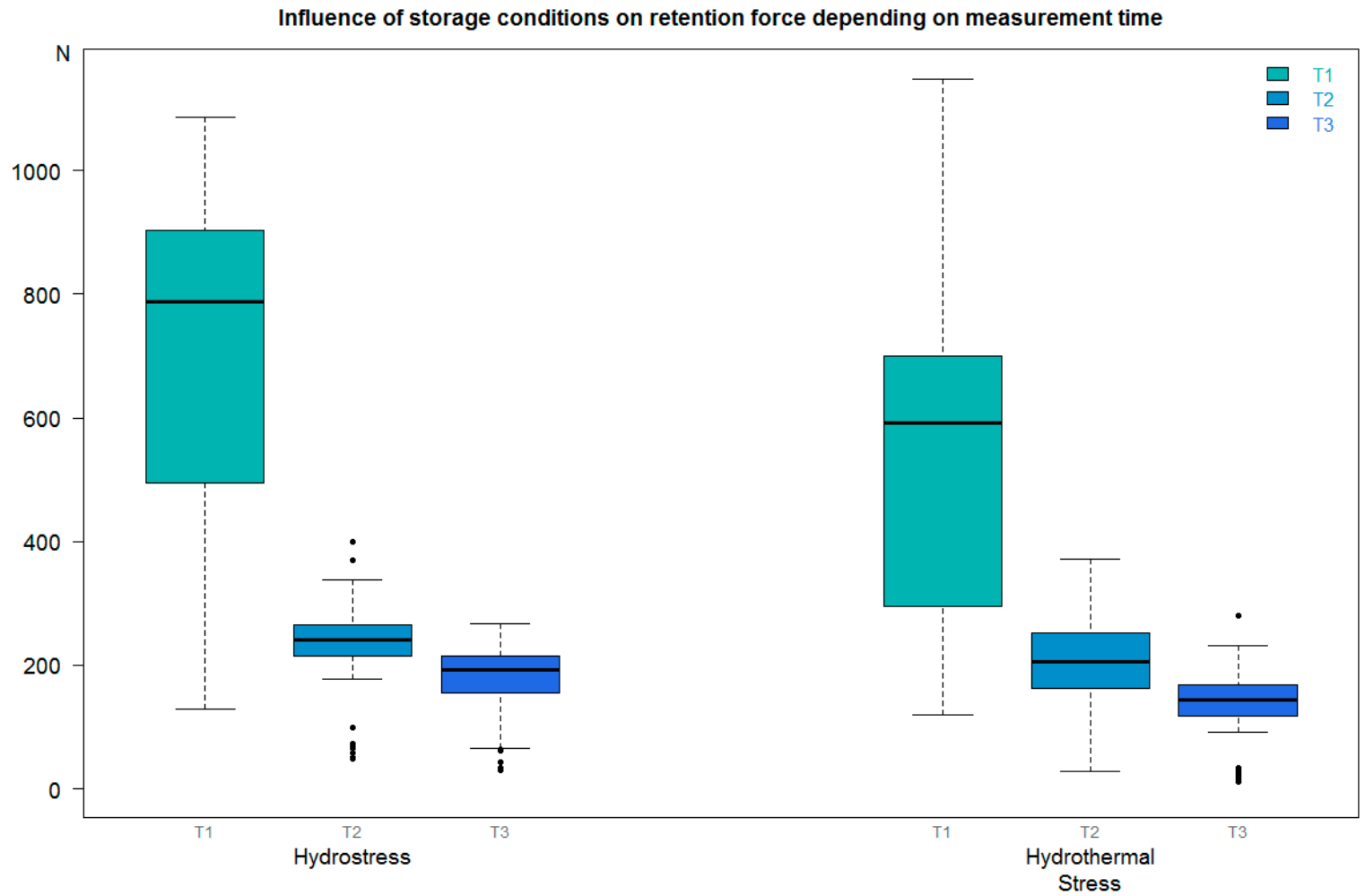

Figure 3. Comparison of the retention force at three retention measurement time-points T1-T3 after various storage conditions independent of the luting materials. For a description of the boxplot, see Figure 2. 
Table 8. Descriptive data of the statistical evaluation of the retention force at $\mathrm{T} 2$ independent of the storage conditions (in N).

\begin{tabular}{cccccccc}
\hline \multirow{2}{*}{ Luting Material } & \multicolumn{7}{c}{ T2 } \\
\cline { 2 - 7 } & Minimum & 1st Quartile & Median & Mean Value & SD & 3rd Quartile & Maximum \\
\hline RelyX Temp Bond NE & 27.28 & 38.89 & 49.09 & 52.21 & 19.11 & 65.85 & 98.55 \\
Meron & 172.90 & 190.90 & 213.60 & 223.30 & 36.64 & 253.90 & 295.50 \\
Fuji I & 192.30 & 232.20 & 251.40 & 258.20 & 44.51 & 292.50 & 338.30 \\
Harvard & 206.70 & 225.70 & 258.10 & 270.80 & 46.68 & 308.70 & 340.30 \\
Fuji II & 203.20 & 231.50 & 242.40 & 259.90 & 46.07 & 272.00 & 370.60 \\
Fuji Plus & 159.40 & 209.10 & 249.20 & 242.70 & 42.93 & 265.10 & 325.30 \\
Bifix Temp & 99.47 & 137.70 & 205.00 & 186.10 & 53.69 & 214.70 & 275.90 \\
Ketac Cem Plus & 128.90 & 180.00 & 229.10 & 236.60 & 75.84 & 255.30 & 399.30 \\
\hline
\end{tabular}

The lowest median retention force at T3 was achieved by RelyX Temp Bond NE (30.98 N; IQR 22.63-47.93 N), and the highest median retention force was achieved by Fuji Plus (188.60 N; IQR 164.90-209.10 N). The results can be found in Table 9 and Figure 3.

Table 9. Descriptive data of the statistical evaluation of the retention force at $\mathrm{T} 3$ independent of the storage conditions (in N).

\begin{tabular}{cccccccc}
\hline \multirow{2}{*}{ Luting Material } & \multicolumn{7}{c}{ T3 } \\
\cline { 2 - 8 } & Minimum & 1st Quartile & Median & Mean Value & SD & 3rd Quartile & Maximum \\
\hline RelyX Temp Bond NE & 10.45 & 22.63 & 30.98 & 35.64 & 19.15 & 47.93 & 66.78 \\
Meron & 131.90 & 142.40 & 179.30 & 173.30 & 31.27 & 190.10 & 244.50 \\
Fuji I & 91.93 & 129.40 & 165.30 & 182.10 & 61.05 & 237.30 & 279.40 \\
Harvard & 140.20 & 153.50 & 185.30 & 185.30 & 30.48 & 211.60 & 234.00 \\
Fuji II & 131.20 & 154.80 & 178.80 & 180.00 & 34.37 & 207.50 & 231.70 \\
Fuji Plus & 132.80 & 164.90 & 188.60 & 187.30 & 31.77 & 209.10 & 244.20 \\
Bifix Temp & 92.92 & 102.40 & 158.90 & 155.70 & 48.12 & 194.60 & 232.40 \\
Ketac Cem Plus & 116.20 & 132.10 & 150.60 & 150.70 & 26.52 & 164.10 & 204.10 \\
\hline
\end{tabular}

3.4. Comparisons of Retention Forces at T1, T2, and T3 for Storage Conditions Independent of Luting Materials

At each retention measurement time-point (T1, T2, and T3), the retention force after storage under hydrostress was conspicuously higher than after storage under hydrothermal stress (Figure 3 , Tables 10-12).

Table 10. Descriptive data of the statistical evaluation of the retention force at $\mathrm{T} 3$ independent of the luting materials (in $\mathrm{N}$ ).

\begin{tabular}{cccccccc}
\hline \multirow{2}{*}{ Storage Condition } & \multicolumn{7}{c}{ T1 } \\
\cline { 2 - 7 } & Minimum & 1st Quartile & Median & Mean Value & SD & 3rd Quartile & Maximum \\
\hline Hydrostress & 128.60 & 494.90 & 788.40 & 693.10 & 263.76 & 899.80 & 1086.00 \\
Hydrothermal stress & 119.70 & 302.70 & 590.80 & 542.30 & 264.25 & 699.10 & 1148.00 \\
\hline
\end{tabular}

Table 11. Descriptive data of the statistical evaluation of the retention force at $\mathrm{T} 3$ independent of the luting materials (in $\mathrm{N}$ ).

\begin{tabular}{cccccccc}
\hline \multirow{2}{*}{ Storage Condition } & \multicolumn{7}{c}{ T2 } \\
\cline { 2 - 8 } & Minimum & 1st Quartile & Median & Mean Value & SD & 3rd Quartile & Maximum \\
\hline Hydrostress & 47.93 & 214.30 & 241.30 & 231.00 & 75.11 & 265.50 & 399.30 \\
Hydrothermal stress & 27.28 & 162.80 & 205.00 & 201.40 & 85.78 & 251.20 & 370.60 \\
\hline
\end{tabular}


Table 12. Descriptive data of the statistical evaluation of the retention force at $\mathrm{T} 3$ independent of the luting materials (in $\mathrm{N}$ ).

\begin{tabular}{cccccccc}
\hline \multirow{2}{*}{ Storage Condition } & \multicolumn{7}{c}{ T3 } \\
\cline { 2 - 7 } & Minimum & 1st Quartile & Median & Mean Value & SD & 3rd Quartile & Maximum \\
\hline Hydrostress & 29.16 & 155.90 & 191.40 & 175.30 & 58.05 & 214.00 & 267.50 \\
Hydrothermal stress & 10.45 & 116.80 & 142.90 & 137.20 & 55.74 & 167.60 & 279.40 \\
\hline
\end{tabular}

\section{Discussion}

The success rates after dental implant treatment are high [23,34,35], and the need for future removal and reparation of implant-fixed restorations will increase [11]. The choice of cement for implant-fixed restorations can influence implant stability after restoration removal.

The retention of crowns on abutments is achieved by a combination of height and form of an abutment, surface roughness of crown and abutment, the luting material [29,36], aging, and the number of recementations. The present in vitro study was performed to observe only three of these factors: the influence of the luting material types, storage conditions (aging), and number of recementations. All other parameters, such as materials, size, and form of the abutment and crown, were standardized. This is why the surface roughness of the crown and abutment were not measured. Titanium abutments were chosen for the present in vitro study because the material of the abutments influences the accumulation of bacteria on the abutments [37] as well as the quality and quantity of marginal soft tissue [14]. Abrahamsson et al. [14] observed that titanium increased new soft tissue formation. Cobalt-chromium crowns were investigated because they are low-cost and have good corrosion resistance and higher hardness [30]. However, cobalt-chromium crowns exhibit lower detail accuracy and higher shrinkage after casting than gold alloys [30]. The superstructure geometry and related surface peculiarities influenced the mechanical behavior of the various abutment-prosthesis (crown) connections [38,39]. A conical connection between abutment and crown was performed because in vivo studies revealed significantly lower bacterial counts in the peri-implant sulci and inside the connections in the internal hexagons of the external collar connection and conical connection groups [4,40]. Clinical experience was considered in the selection of the luting materials for the present study [28], which were: the commonly used conventional permanent zinc phosphate and the glass ionomer cements [41], popular in the last decade, permanent resin-modified glass ionomer cements [41], and temporary cements [31]. The permanent zinc phosphate Harvard cement served as a control, the "gold standard for comparisons with all other luting agents"; we are grateful for its long and successful clinical history [41]. A sample size calculation was not carried out. Per se $n=8$ samples per cement group and storage conditions were prepared. This number of cases was found sufficient in previous studies for cement adhesion tests and retention tests of temporary or permanent luting agents for implant-retained dentures [42,43]. A post-hoc power analysis confirmed the investigation's sample size choice of $n=8$ per storage condition and luting material as sufficient. The retention forces of all luting materials at T1 were compared to that of the reference material (Harvard cement) for each storage condition separately, and when taking into account the problem of multiple testing by usage of the Holm-Boferroni method. It could be shown that the pairwise comparisons had a post-hoc effect power ranging between $84 \%$ and $99 \%$. The aging of the tested specimens for retention force evaluation was performed with HS and HTS that made the present study comparable to similar investigations [27,44-46]. Data from the present study clearly demonstrated that the bonding capacities of the various luting materials had a remarkable influence on the retention force only after the first cementation. The highest retention force was achieved by the permanent glass ionomer cement Meron; however, Kunt et al. [27] reported that Meron had a more than three times lower retention force (pull-off force) than that measured in the present study and a lower pull-off force compared to the permanent zinc oxide phosphate cement Adhesor. The variation of these results can be explained by the lower pull rate $(0.5 \mathrm{~mm} / \mathrm{min}$ versus $1.0 \mathrm{~mm} / \mathrm{min}$ in the present study), the use of another metal for the crown, the smaller size (diameter $\times$ height) of the abutment $(3.7 \mathrm{~mm} \times 5.0 \mathrm{~mm}$ versus 
$4.8 \mathrm{~mm} \times 5.3 \mathrm{~mm}$ in the present study), and the conventional casting process for the crown production (versus the laser-sintered process in the present study). Kilicarslan and Ozkan [47] found significantly higher pull-off forces for laser-sintered superstructures on implant abutments compared to those of conventional castings. The eugenol-free temporary Rely X Temp Bond NE showed the lowest retention force. This finding agrees with those of other studies [27,44]. Michalakis et al. [44] found a significantly lower retention force of eugenol-free temporary luting materials than for temporary composite-based cement Bifix Temp. Kunt et al. [27] also showed the lowest retention force for the eugenol-free temporary cement Cavex Temporary, which belongs to the same material class as Rely $\mathrm{X}$ Temp Bond NE. In the present study, the permanent methacrylate-based resin-modified glass ionomer cements and permanent zinc phosphate cement showed small differences in retention force median values. Korsch et al. [48] and Pesce, Canullo et al. [4] observed that methacrylate cements have low viscosity and can leave more excess cement in the implant-mucosal interface, causing bleeding and inducing biofilm formation [4,48]. With respect to the various storage conditions (artificial aging), only at retention measurement time-point $\mathrm{T} 3$ could a locally significant difference of the retention force between groups (S1 and S2) be determined. This finding agrees with the results of a study by Michalakis et al. [44], where all specimens showed a reduction in the maximum retention force (pull-off force) after HTS. However, Dudley et al. [45] showed that the glass ionomer cement (Ketac Cem) and the eugenol-free provisional cement (Temp Bond NE) showed no significant differences in terms of maximum retention force with an increasing number of thermocycles [45], possibly due to the absence of the retentions and recementations between the examinations. With increasing retentions and recementations, the retention (pull-off) force for all test specimens was reduced in the present experiments. Obviously, the characteristics of cemented implant-supported cobalt-chromium crown internal surfaces in the present study were altered after the retention and surface conditioning with sandblasting, significantly reducing the crown-cement-abutment bonding interaction and consequently altering the retention force during the second and third retention in all of the cement groups, independent of the luting materials. Mundt et al. [30] used a similar sandblasting model of the cobalt-chromium crown inner surfaces with $50 \mathrm{~mm}$ particle size aluminum oxide at a pressure of 2.5 bar, followed by rinsing and drying, reporting similar observations. However, an in vitro study investigating the retention of implant-supported CAD/CAM metal copings after cementation with temporary cements and recementation with the permanent resin cement Panavia showed that the bond strength of the adhesive resins was not affected after minor surface alterations occurring during recementation [46]. The differences in the results can be explained by different study designs: the initial cementation was performed with temporary cement; however, the recementations were performed with temporary resin cements. In the present study, by contrast, the initial cementation and following recementations were performed with the same luting materials. It appears that the effect of decreasing retention force due to recementation can be altered by using another type of luting material for the subsequent recementations. Perhaps, resin cements are more appropriate for this purpose. In some studies, it was observed that the resin cement Panavia contains 10-methacryloyloxydecyl dihydrogen phosphate (MDP) and provides the highest retentive values due the chemical bond with metallic oxides $[46,49]$.

We rejected the null hypothesis of this in vitro study, i.e., that there are no differences between the mean retention forces of the different luting materials at three retention measurement time-points of the implant-supported cobalt-chromium crowns cemented and recemented with the same luting materials.

The present study has some limitations: only hydro- and hydrothermal stress were performed to induce artificial aging. Unfortunately, this aging is not completely appropriate for the dynamic nature of intraoral aging [49]. Second, surface roughness was not measured. Another limitation was the type of the retention force due decementation. The force within the pull-off test was always applied along the vertical prosthetic axis at a constant speed, and this is almost never possible in clinical practice $[12,49]$. In future research, the surface roughness before and after every recementation trial should be measured. Furthermore, the alterations of the crown surfaces after multiple recementations 
should be studied [30]. Most likely, for future research, special alternative methods and condition agents for preserving cobalt-chromium crown internal surface conditions have to be tested, possibly providing an alternative to sandblasting. Additional masticatory simulation in experiments can improve the simulation of intraoral aging, because the nature of these loads are oblique occlusion forces, and the stress state during mechanical fatigue by thermal deformation is different [49] compared to hydro- and hydrothermal stress. Recementation of cemented implant-supported cobalt crowns with other luting materials should be performed. The results of in vitro studies, such as this study, should be included in a database regarding luting material characteristics and should be correctly interpreted. There remains a need for guidelines regarding cement or cementation procedures and for generating accurate information regarding the clinical outcomes of cement-retained implant-supported fixed restorations, particularly regarding the ideal type of cement that would provide stability and maintain retrievability [18], ensuring biological compatibility and simple removal of excess cement using radiographic view [50] and controlled destruction of dental cements [11].

\section{Conclusions}

Sandblasting and recementation of implant-supported cobalt-chromium crowns with the same luting materials resulted in a reduction of the retention force independent of the luting material. Within the limitations of this study, it can be concluded that a material-specific ranking of cemented implant-supported cobalt-chromium crown retention forces was observed due to the first decementation. Clinical research is needed to confirm these findings.

Author Contributions: Conceptualization, A.P.; Methodology, C.B., A.P.; Validation, F.R., B.G.; Formal Analysis, B.G.; Investigation, F.R.; Data Curation, F.R., B.G., C.B.; Writing-Original Draft Preparation, E.A.N., B.G.; Writing-Review \& Editing, E.A.N., W.H.A., B.G., C.B., A.P.; Supervision, A.P.; Project Administration, A.P.

Funding: This research received no external funding.

Acknowledgments: The authors thank J. Hannibal from Winnopal, Elze, Germany, for his technical support and 3M Oral Care, Seefeld, Germany, and Voco, Cuxhaven, Germany, for the materials provided and for financial support of this study. The authors thank Frank Krummenauer for advising and accompanying the statistical evaluations and for valuable comments.

Conflicts of Interest: The authors declare that they have no conflict of interests.

\section{References}

1. Pommer, B.; Valkova, V.; Ubaidha Maheen, C.; Furhauser, L.; Rausch-Fan, X.; Seeman, R. Scientific interests of 21st century clinical oral implant research: Topical trend analysis. Clin. Implant. Dent. Relat. Res. 2016, 18, 850-856. [CrossRef] [PubMed]

2. Wang, Q.Q.; Dai, R.; Cao, C.Y.; Fang, H.; Han, M.; Li, Q.L. One-time versus repeated abutment connection for platform-switched implant: A systematic review and meta-analysis. PLoS ONE 2017, 12, 0186385. [CrossRef] [PubMed]

3. Yeung, S.C. Biological basis for soft tissue management in implant dentistry. Aust. Dent. J. 2008, 53 (Suppl. 1), S39-S42. [CrossRef] [PubMed]

4. Pesce, P.; Canullo, L.; Grusovin, M.G.; de Bruyn, H.; Cosyn, J.; Pera, P. Systematic review of some prosthetic risk factors for periimplantitis. J. Prosthet. Dent. 2015, 114, 346-350. [CrossRef] [PubMed]

5. Cooper, L.F.; Stanford, C.; Feine, J.; McGuire, M. Prospective assessment of CAD/CAM zirconia abutment and lithium disilicate crown restorations: 2.4 year results. J. Prosthet. Dent. 2016, 116, 33-39. [CrossRef] [PubMed]

6. Modi, R.; Mittal, R.; Kohli, S.; Singh, A.; Sefa, I. Screw versus cement retained prosthesis: A review. Int. J. Adv. Health Sci. 2014, 1, 26-32.

7. Wittneben, J.G.; Millen, C.; Bragger, U. Clinical performance of screw-versus cement-retained fixed implant-supported reconstructions-A systematic review. Int. J. Oral Maxillofac. Implants 2014, 29, 84-98. [CrossRef] [PubMed]

8. Esposito, M.; Bressan, E.; Grusovin, M.G.; D'Avenia, F.; Neumann, K.; Sbricoli, L.; Luongo, G. Do repeated changes of abutments have any influence on the stability of peri-implant tissues? One-year post-loading results from a multicentre randomised controlled trial. Eur. J. Oral Implantol. 2017, 10, 57-72. [PubMed] 
9. Charyeva, O.; Altynbekov, K.; Zhartybaev, R.; Sabdanaliev, A. Long-term dental implant success and survival-A clinical study after an observation period up to 6 years. Swed. Dent. J. 2012, 36, 1-6. [PubMed]

10. Sakka, S.; Baroudi, K.; Nassani, M.Z. Factors associated with early and late failure of dental implants. J. Investig. Clin. Dent. 2012, 3, 258-261. [CrossRef] [PubMed]

11. Bishti, S.; Tuna, T.; Agrawal, G.; Pich, A.; Wolfart, S. Modified glass ionomer cement with "remove on demand" properties: An in vitro study. Dent. J. 2017, 5, 9. [CrossRef] [PubMed]

12. Schierano, G.; Manzella, C.; Menicucci, G.; Parrotta, A.; Zanetti, E.M.; Audenino, A.L. In vitro standardization of two different removal devices in cemented implant prosthesis. Clin. Oral Implants Res. 2016, 27, 1026-1030. [CrossRef] [PubMed]

13. Christensen, R.M. Exploration of ductile, brittle failure characteristics through a two-parameter yield/failure criterion. Mater. Sci. Eng. A 2005, 394, 417-424. [CrossRef]

14. Abrahamsson, I.; Berglundh, T.; Glantz, P.; Lindhe, J. The mucosal attachment at different abutments. An experimental study in dogs. J. Clin. Periodontol. 1998, 25, 721-727. [CrossRef] [PubMed]

15. Mehl, C.; Harder, S.; Wolfart, M.; Kern, M.; Wolfart, S. Retrievability of implant-retained crowns following cementation. Clin. Oral Implants Res. 2008, 19, 1304-13011. [CrossRef] [PubMed]

16. Sahu, N.; Lakshmi, N.; Azhagarasan, N.S.; Agnihotri, Y.; Rajan, M.; Hariharan, R. Comparison of the effect of implant abutment surface modifications on retention of implant-supported restoration with a polymer based cement. J. Clin. Diagn. Res. 2014, 8, 239-242. [PubMed]

17. Rodiger, M.; Rinke, S.; Ehret-Kleinau, F.; Pohlmeyer, F.; Lange, K.; Burgers, R.; Gersdorff, N. Evaluation of removal forces of implant-supported zirconia copings depending on abutment geometry, luting agent and cleaning method during re-cementation. J. Adv. Prosthodont. 2014, 6, 233-240. [CrossRef] [PubMed]

18. Chaar, M.S.; Att, W.; Strub, J.R. Prosthetic outcome of cement-retained implant-supported fixed dental restorations: A systematic review. J. Oral Rehabil. 2011, 38, 697-711. [CrossRef] [PubMed]

19. Galvan, G.; Kois, J.C.; Chaiyabutr, Y.; Kois, D. Cemented implant restoration: A technique for minimizing adverse biologic consequences. J. Prosthet. Dent. 2015, 114, 482-485. [CrossRef] [PubMed]

20. Rosentritt, M.; Schneider-Feyrer, S.; Behr, M.; Preis, V. In vitro shock absorption tests on implant-supported crowns: Influence of crown materials and luting agents. Int. J. Oral Maxillofac. Implants 2018, 33, 116-122. [CrossRef] [PubMed]

21. Lang, N.P.; Pjetursson, B.E.; Tan, K.; Bragger, U.; Egger, M.; Zwahlen, M. A systematic review of the survival and complication rates of fixed partial dentures (FPDs) after an observation period of at least 5 years. II. Combined tooth-implant-supported FPDs. Clin. Oral Implants Res. 2004, 15, 643-653. [CrossRef] [PubMed]

22. Sheets, J.L.; Wilcox, C.; Wilwerding, T. Cement selection for cement-retained crown technique with dental implants. J. Prosthodont. Off. J. Am. Coll. Prosthodont. 2008, 17, 92-96. [CrossRef] [PubMed]

23. Amorfini, L.; Storelli, S.; Mosca, D.; Scanferla, M.; Romeo, E. Comparison of cemented vs. screw-retained, customized computer-aided design/computer-assisted manufacture zirconia abutments for esthetically located single-tooth implants: A 10-year randomized prospective study. Int. J. Prosthodont. 2018, 31, 359-366. [CrossRef] [PubMed]

24. Hebel, K.S.; Gajjar, R.C. Cement-retained versus screw-retained implant restorations: Achieving optimal occlusion and esthetics in implant dentistry. J. Prosthet. Dent. 1997, 77, 28-35. [CrossRef]

25. Farzin, M.; Torabi, K.; Ahangari, A.H.; Derafshi, R. Effect of abutment modification and cement type on retention of cement-retained implant supported crowns. J. Dent. 2014, 11, 256-262.

26. Nissan, J.; Snir, D.; Rosner, O.; Kolerman, R.; Chaushu, L.; Chaushu, G. Reliability of retrievable cemented implant-supported prostheses. J. Prosthet. Dent. 2016, 115, 587-591. [CrossRef] [PubMed]

27. Kunt, G.E.; Ceylan, G.; Yilmaz, N.; Kücük, B.E. Luting agent effectiveness on implant crown retention. Int. J. Oral Implantol. Clin. Res. 2011, 2, 7-11. [CrossRef]

28. Shadid, R.; Sadaqa, N. A comparison between screw- and cement-retained implant prostheses. A literature review. J. Oral Implantol. 2012, 38, 298-307. [CrossRef] [PubMed]

29. Bresciano, M.; Schierano, G.; Manzella, C.; Screti, A.; Bignardi, C.; Preti, G. Retention of luting agents on implant abutments of different height and taper. Clin. Oral Implants Res. 2005, 16, 594-598. [CrossRef] [PubMed]

30. Mundt, T.; Heinemann, F.; Golecki, G.; Schwahn, C.; Biffar, R. Retention force of secondary crowns to copings after temporary cementation: The effect of crown material and luting agent. Biomed. Tech. Biomed. Eng. 2010, 55, 335-340. [CrossRef] [PubMed] 
31. Breeding, L.C.; Dixon, D.L.; Bogacki, M.T.; Tietge, J.D. Use of luting agents with an implant system: Part I. J. Prosthet. Dent. 1992, 68, 737-741. [CrossRef]

32. Heinemann, F.; Mundt, T.; Biffar, R. Retrospective evaluation of temporary cemented, tooth and implant supported fixed partial dentures. J. Cranio-Maxillo-Facial Surg. 2006, 34 (Suppl. 2), 86-90. [CrossRef]

33. Wolfart, M.; Wolfart, S.; Kern, M. Retention forces and seating discrepancies of implant-retained castings after cementation. Int. J. Oral Maxillofac. Implants 2006, 21, 519-525. [PubMed]

34. Läkamp, J.; Läkamp, M.; Meyer, U.; Boisserée, W.; Grunert, I.; Schupp, W. Funktionelle Implantologie, 1st ed.; Quintessenz Verlag: Berlin, Germany, 2016; pp. 1-35, ISBN 978-3-8687-312-8.

35. Lewis, S.G.; Llamas, D.; Avera, S. The UCLA abutment: A four-year review. J. Prosthet. Dent. 1992, 67, 509-515. [CrossRef]

36. Bernal, G.; Okamura, M.; Munoz, C. The effects of abutment taper, length and cement type on resistance to dislodgement of cement-retained, implant-supported restorations. J. Prosthodont. 2003, 12, 111-115. [CrossRef]

37. Cho, H.-W.; Dong, J.-K.; Jin, T.-H.; Oh, S.-C.; Lee, H.-H.; Lee, J.-W. A study on the fracture strength of implant-supported restorations using milled ceramic abutments and all-ceramic crowns. Int. J. Prosthodont. 2002, 15, 9-13. [PubMed]

38. Gehrke, S.A. Importance of crown height ratios in dental implants on the fracture strength of different connection designs: An in vitro study. Clin. Implant Dent. Relat. Res. 2015, 17, 790-797. [CrossRef] [PubMed]

39. Geringer, A.; Diebels, S.; Nothdurft, F.P. Influence of superstructure geometry on the mechanical behavior of zirconia implant abutments: A finite element analysis. Biomed. Tech. Biomed. Eng. 2014, 59, 501-506. [CrossRef] [PubMed]

40. Canullo, L.; Penarrocha-Oltra, D.; Soldini, C.; Mazzocco, F.; Penarrocha, M.; Covani, U. Microbiological assessment of the implant-abutment interface in different connections: Cross-sectional study after 5 years of functional loading. Clin. Oral Implants Res. 2015, 26, 426-434. [CrossRef] [PubMed]

41. Jivraj, S.A.; Kim, T.H.; Donovan, T.E. Selection of luting agents, part 1. J. Calif. Dent. Assoc. 2006, 34, $149-160$. [PubMed]

42. Alvarez-Arenal, A.; Gonzalez-Gonzalez, I.; deLlanos-Lanchares, H.; Brizuela-Velasco, A.; Ellacuria-Echebarria, J. The selection criteria of temporary or permanent luting agents in implant-supported prostheses: In vitro study. J. Adv. Prosthodont. 2016, 8, 144-149. [CrossRef] [PubMed]

43. Pan, Y.; Ramp, L.; Lin, C.; Liu, P. Comparison of 7 luting protocols and their effect on the retention and marginal leakage of a cemented-retained dental implant restoration. Int. J. Oral Maxillofac. Implants 2006, 21, 587-592. [PubMed]

44. Michalakis, K.; Pissiotis, A.; Kang, K.; Hirayama, H.; Garefis, P.; Petridis, H. The effect of thermal cycling and air abrasion on cement failure loads of 4 provisional luting agents used for the cementation of implant-supported fixed partial dentures. Int. J. Oral Maxillofac. Implants 2007, 22, 569-574. [PubMed]

45. Dudley, J.; Richards, L.; Abbott, J. Retention of cast crown copings cemented to implant abutments. Aust. Dent. J. 2008, 53, 332-339. [CrossRef] [PubMed]

46. Safari, S.; Hosseini Ghavam, F.; Amini, P.; Yaghmaei, K. Effects of abutment diameter, luting agent type, and re-cementation on the retention of implant-supported CAD/CAM metal copings over short abutments. J. Adv. Prosthodont. 2018, 10, 1-7. [CrossRef] [PubMed]

47. Kilicarslan, M.; Ozkan, P. Evaluation of retention of cemented laser-sintered crowns on unmodified straight narrow implant abutments. Int. J. Oral Maxillofac. Implants 2013, 28, 381-387. [CrossRef] [PubMed]

48. Korsch, M.; Obst, U.; Walther, W. Cement-associated peri-implantitis: A retrospective clinical observational study of fixed implant-supported restorations using a methacrylate cement. Clin. Oral Implants Res. 2014, 25, 797-802. [CrossRef] [PubMed]

49. Nejatidanesh, F.; Savabi, O.; Jabbari, E. Effect of surface treatment on the retention of implant-supported zirconia restorations over short abutments. J. Prosthet. Dent. 2014, 112, 38-44. [CrossRef] [PubMed]

50. Nematollahi, F.; Beyabanaki, E.; Alikhasi, M. Cement selection for cement-retained implant-supported prostheses: A literature review. J. Prosthodont. 2016, 25, 599-606. [CrossRef] [PubMed]

(C) 2018 by the authors. Licensee MDPI, Basel, Switzerland. This article is an open access article distributed under the terms and conditions of the Creative Commons Attribution (CC BY) license (http:// creativecommons.org/licenses/by/4.0/). 